\title{
Improving Human-Reviews Interaction: A Study of the Role, Use, and Place of Online Reviews
}

\author{
Claudia lacob \\ University of Portsmouth \\ Portsmouth, UK \\ claudia.iacob@port.ac.uk
}

\author{
Shamal Faily \\ Bournemouth University \\ Poole, UK \\ sfaily@bournemouth.ac.uk
}

\begin{abstract}
The use and benefits of online reviews are undeniable, yet the interaction means available for buyers when consulting reviews remain limited. This study aims to provide a better understanding of the role and use of online reviews, presenting a set of design ideas for designing user interfaces that better support online buyers in consulting reviews. Drawing on interviews with active online review users, we describe the main role reviews play in their purchase decisions online and offline, the strategies they use for making sense of the ever growing number of reviews, and the characteristics they associate with a usable online review. We present the relevant characteristics of a reviewer's portrait, and identify the role online reviews play in the broader landscape of e-commerce together with other similar tools such as forums or product specifications.
\end{abstract}

Online reviews; e-commerce; communications

\section{INTRODUCTION}

Online reviews are ubiquitous; TripAdvisor currently hosts more than 250 million reviews from travellers around the world (TripAdvisor LLC 2016), while Amazon's review set includes more than 35 million reviews (Leskovec 2016). Even though reviews are growing as powerful tools in all aspects of ecommerce (Chatterjee 2001), the interaction means available to make sense and query them remain limited.

Tourism related sites such as booking.com or expedia.com allow travellers to filter reviews by the profile of the reviewer (e.g. families, business traveler, etc.), and the language they were written in. They also allow sorting of reviews by the date posted, and their rating. In addition, they typically provide average ratings for specific characteristics of the service (e.g. location, cleanliness, staff, etc.). However, the content of reviews is rarely structured in any way and, when it is, this is often restricted to a pros and a cons section. For example, Amazon presents two sets of reviews for each product by default - the ones rated most helpful and the most recent ones. An additional option of seeing all the reviews of a product is available with the possibility of sorting them by a starred rating, and filtering the positive (rated 4 or above) or critical ones (rated 3 or below). We believe that such interactions are not proportionally user-friendly with the benefits gained from consulting reviews.

This paper presents a study of the role, use, and place of online reviews, in order to identify and explore areas where human-reviews interaction can be improved. We begin in Section 2 by describing the related work on types of review users, their interactions, and context of use, before presenting the approach taken to conduct our study in Section 3. In Section 4, we then present five themes resulting from our study: the role reviews play in decisionmaking, the characteristics of usable reviews, review sense-making strategies, reviewer details of interest, and the place of reviews among other e-commerce tools. We conclude in Section 5 by presenting the design implications of our study to both authors and consumers of reviews.

\section{RELATED WORK}

In this paper, we define an online review as text written by a product user that details pros and cons of a product, with an optional assessment and recommendation for potential buyers (Hedegaard and Simonsen 2013). Due to their strong presence and impact in the world of e-commerce, different aspects of reviews have been the subject to 
extensive research. For example, research has focused on the impact reviews make on business' sales and reputation (Forman et al. 2006; Ye et al. 2009), the profiles of the reviews' writers and possible incentives for writing reviews (Yoo and Gretzel 2011), the content of reviews and ways to summarise them (Jin et al. 2014), and the impact they have on the consumers' decision to purchase a product or service online (Ye et al. 2009). There has been comparatively little work done on understanding the profile of active online reviews users: what motivates them to make use of reviews, how they make sense of the large volume of reviews, and what place online reviews take in the broader landscape of e-commerce. This gap has consequently led to little change in the design of the interaction with reviews, with sites hosting reviews still offering limited interaction means. We synthesise below results of related work on the profiles of active review users, the interaction means available today for consulting reviews, and the changing context of online reviews.

\subsection{Review Users: Authors and Consumers}

Before we consider what motivates 'users' to interact with reviews, we should extend this notion of review user to consider review authors as well as review consumers. Invariably, there are more of the latter than there are of the former. Not all product users are interested in submitting a review, and a lack of time and interest is a common bar to review creation (Yoo and Gretzel 2011). When review authors are motivated to contribute a review, this might be for a number of reasons. In some cases, it is because authors want to help others, rather than to satisfy any extrinsic goal (Yoo et al. 2013). In others, authors describe the advantages and disadvantages by venting some happiness or unhappiness associated with the product (Hu et al. 2008). However, not all review authors are legitimate. There have been numerous cases of fake online identities ("sock puppets") being created with the express purpose of creating fake reviews. In some cases, authors fabricate feedback to increase awareness of their own products or services (Dohse 2013). In other cases, authors or paid proxies use negative reviews to boost ratings or undermine competitors (BBC News 2015).

Review consumers appear to make judgments about reviews based on the identity of the review author (Forman et al. 2006). While the background of the author has only a minor impact on the review's credibility (Vermeulen and Seegers 2009), it can be a factor in ascertaining how helpful a review might be (Huang et al. 2015). As such, consumers do appear to care about contextual information such as author's history or 'karma', and the range of his exposure with the product under review (Hu et al. 2008). However, as useful as detailed information about the range of usage is, reviews often don't contain sufficient information to allow reviewers to re-establish a model of specific situations of use (Hedegaard and Simonsen 2013).

\subsection{Interacting with reviews}

Although people interact with a greater number of varied reviews, the means afforded by review sites for interacting with them remains basic. For example, in addition to review text, reviews typically include some form of summative score or rating to help them quickly make sense of many reviews. However, such scores are not always reliable, and the average review score does not reflect product quality (Hu et al. 2008). Moreover, unless a review consumer is engaged with the reviews, it's likely that $s /$ he will conform to the consensus of these reviews, irrespective of the quality of the reviews' content (Lee et al. 2008). In lieu of any other affordances, review consumers rely on reviews, which are critical, with review consumers finding negative reviews being more credible than positive ones (Chatterjee 2001). Review consumers also find long reviews useful (Gretzel et al. 2007), but the characteristics of a useful review vary based on the characteristics of the reviewed product. For example, (Mudambi and Schuff 2010) report that reviews that receive a moderate score have been found to be most useful when product characteristics are difficult to assess before they are used (experience goods). Additionally, reviews that are long are most useful for products with characteristics that can be evaluated before use (search goods). It has, however, been suggested that consumers may not read long reviews in their entirety, due to other demands on their attention such as advertisements (Huang et al. 2015).

\subsection{The Changing Context of Reviews}

While our definition of reviews suggests only potential buyers use them, the contexts within which reviews are used appear to be growing. The increased visibility of reviews by e-commerce consumers means that, irrespective of their content, they are becoming a tool for increasing awareness of products and services; awareness is increased irrespective of whether reviews are positive or negative (Vermeulen and Seegers 2009). This impact is particularly felt when dealing with the products of unknown quality (Luca 2011), although the loyalty that author consumers have towards a brand can mitigate the effect of negative reviews (Chatterjee 2001). 


\begin{tabular}{|c|c|c|c|}
\hline & Age & Profession & Read reviews for \\
\hline $\mathrm{P1}$ & $>40(\mathrm{~m})$ & Helicopter mechanic & Anything online \\
\hline P2 & $>40(\mathrm{~m})$ & Researcher in security & Books and travelling \\
\hline P3 & $>30(\mathrm{f})$ & $\begin{array}{l}\text { Researcher in software } \\
\text { design }\end{array}$ & $\begin{array}{l}\text { Services and products } \\
\text { never used before }\end{array}$ \\
\hline $\mathrm{P} 4$ & $>20(\mathrm{~m})$ & $\begin{array}{l}\text { BSc student in Computer } \\
\text { Science }\end{array}$ & $\begin{array}{l}\text { Electronics, computer- } \\
\text { related items }\end{array}$ \\
\hline P5 & $>20(\mathrm{~m})$ & $\begin{array}{l}\text { BSc student in Computer } \\
\text { Science }\end{array}$ & Anything above $£ 10$ \\
\hline P6 & $>30(\mathrm{f})$ & $\begin{array}{l}\text { Researcher in Artificial } \\
\text { Intelligence }\end{array}$ & $\begin{array}{l}\text { Products never used be- } \\
\text { fore and travelling }\end{array}$ \\
\hline P7 & $>20(\mathrm{f})$ & $\begin{array}{l}\text { Teaching assistant in } \\
\text { Psychology }\end{array}$ & Anything online \\
\hline P8 & $>20(\mathrm{f})$ & $\begin{array}{l}\text { Researcher in Human } \\
\text { Factors }\end{array}$ & Travelling and electronics \\
\hline P9 & $>30(\mathrm{~m})$ & $\begin{array}{l}\text { Researcher in Software } \\
\text { Engineering }\end{array}$ & Electronics and furniture \\
\hline $\mathrm{P} 10$ & $>30(\mathrm{~m})$ & $\begin{array}{l}\text { Researcher in Environ- } \\
\text { mental Engineering }\end{array}$ & Electronics and travelling \\
\hline P11 & $>20(\mathrm{f})$ & Hotel receptionist & Travelling and electronics \\
\hline $\mathrm{P} 12$ & $>30(\mathrm{~m})$ & IT manager & Services and electronics \\
\hline $\mathrm{P} 13$ & $>20(\mathrm{~m})$ & Software developer & Anything online \\
\hline P14 & $>30(\mathrm{~m})$ & $\begin{array}{l}\text { Researcher in } \\
\text { Human Factors }\end{array}$ & Travelling \\
\hline $\mathrm{P} 15$ & $>40(\mathrm{~m})$ & Pilot & Aquarium products \\
\hline P16 & $>20(\mathrm{~m})$ & $\begin{array}{l}\text { MA student in Film Pro- } \\
\text { duction }\end{array}$ & $\begin{array}{l}\text { Travelling and anything } \\
\text { on eBay }\end{array}$ \\
\hline P17 & $>30(\mathrm{~m})$ & $\begin{array}{l}\text { Researcher in Require- } \\
\text { ments Engineering }\end{array}$ & Electronics \\
\hline P18 & $>20(\mathrm{~m})$ & $\begin{array}{l}\text { MSc in Software Engi- } \\
\text { neering }\end{array}$ & $\begin{array}{l}\text { Travelling and anything } \\
\text { on Amazon }\end{array}$ \\
\hline P19 & $>20(\mathrm{~m})$ & $\begin{array}{l}\text { Researcher in Intelligent } \\
\text { Systems }\end{array}$ & Children related items \\
\hline $\mathrm{P} 20$ & $>20(\mathrm{~m})$ & $\begin{array}{l}\text { Researcher in Cyber Se- } \\
\text { curity }\end{array}$ & $\begin{array}{l}\text { Travelling and anything } \\
\text { on Amazon }\end{array}$ \\
\hline P21 & $>30(\mathrm{f})$ & Business Consultant & $\begin{array}{l}\text { Amazon products - } \\
\text { Home appliances, kids } \\
\text { toys and appliances, } \\
\text { books }\end{array}$ \\
\hline P22 & $>30(\mathrm{f})$ & Small business owner & $\begin{array}{l}\text { Travelling, and security } \\
\text { products }\end{array}$ \\
\hline
\end{tabular}

Table 1: Participants demographics: age range, gender $(\mathrm{m} / \mathrm{f})$, profession and the class of products they read reviews for

In these different contexts, reviews are more than just a recommendation that informs purchase decisions. For example, travellers now use reviews to explore different options when planning trips (Gretzel et al. 2007), and researchers are now starting to mine the textual content of reviews for different purposes; these include predicting health inspections for restaurants (Kang et al. 2013), and extracting feature requests and bugs for software products (lacob et al. 2013). It is also possible to mine for usability information (Hedegaard and Simonsen 2013), and use computational linguistic techniques to indirectly improve consumers' interactions with reviews. This was illustrated by (Jin et al. 2014), which demonstrated how summarisation techniques could be used to aggregate information about pairs of reviews; by enabling consumers to quickly focus on specific aspects of a product, new use scenarios were identified.

\section{METHOD}

We conducted semi-structured interviews with 22 active online review consumers. We recruited participants from a snowball sample, beginning with known online review consumers; they participants referred us to other people (friends, colleagues, family) who they thought might be using online reviews in their day-to-day lives. We screened all participants to ensure only those who actively use online reviews when making online or offline purchase decisions were recruited.

The participants' demographics span different age groups, professions, and nationalities (Table 1). Four participants were in their 40s, eight in their 30s, and ten in their 20s. We did not target a specific age range, nor did we intend to exclude any age range; therefore, the sample is not a particularly unusual group. Four of the participants were students lacking a steady income. The majority of participants $(n=18)$ were employed in roles ranging from academic researchers in various disciplines (including security, software design, and environmental research), hotel receptionists, pilots, business consultants, or software developers. The interviews were held in the UK, but the participants were nationals of different countries, including Romania $(n=6)$, UK $(n=4)$, Belgium $(n=2)$, Hungary $(n=2)$, Syria $(n=1)$, Iran $(n=1)$, Turkey $(n=1)$, Ireland $(n=1)$, USA $(n=1)$, Italy $(n=1)$, Zimbabwe $(n=1)$, and Greece $(n=1)$.

Most interviews were run face to face $(n=18)$, with the exception of 4 , which we ran via Skype. The shortest interview length was 15 minutes, 14 seconds (the short length was due to unanticipated language barriers), and the longest was 50 minutes, 9 seconds. Prior to any interview, we screened potential participants (usually via email, prior to scheduling an interview) by asking if they use online reviews before buying products online or offline, or before booking services online or otherwise. Such services included hotel accommodation, restaurants, house repairs, or medical services. We only scheduled interviews with those who pointed out categories of products or services for which they would always consult reviews before purchasing. We did not include participants who described their interaction with online reviews as occasional (e.g. "I sometimes read reviews, but not really") or contextual (e.g. "I read reviews for something this one time").

The interviews were divided into three phases. The first phase focused on the decision to consult reviews. We asked participants about the products and services they usually read reviews for, the characteristics of these products that motivate them to pay an interest in reviews, the reasons they read reviews in the first place, and their online vs. offline practices around online reviews. The second phase focused on the process of consulting reviews. We asked participants about their strategies in making 
sense of the large number of reviews available online, the things they are looking for in reviews, the things they are interested to know about the writer of a review, and the things they associate with a usable review. Finally, the third phase focused on the decision to purchase a product as a result of consulting reviews. We asked participants about the impact reviews have in their purchase decisionmaking, both online and offline.

All interviews were audio recorded and transcribed. A Grounded Theory process [18] was used to analyse the transcripts as they were created. The transcripts were initially open coded by the first author. Together with the second author, the transcripts were iteratively axially and selectively coded. Theoretical saturation, i.e. the point at which no new insights were gleaned from the qualitative data analysis, was reached after analysing transcripts from 19 interviews. Based on the results of this analysis, five themes were identified.

\section{RESULTS}

This section is organised by the five themes emerging from our ground theory analysis: the role reviews play in purchase decisions, the characteristics associated with a usable review, strategies for making sense of reviews, details of interest about the reviewer, and the place reviews hold among other e-commerce tools (i.e. ads, forums, branding, etc).

\subsection{The Role of Reviews}

Having explored the motivations participants have for consulting reviews before or after making a purchase decision, we identified several roles reviews play during human-review interactions.

\subsubsection{Product Exploration}

Participants reported they consult reviews to learn more about products they want to purchase, and especially about those products they are less familiar with - "I did look at a lot of reviews for bikes recently because I didn't know very much about it and I was worried that I might not have the expertise of someone who would know what they are actually looking for" [P2]. For such products (but not exclusively), participants relied on reviews as a starting point in their product exploration. Reviews helped them discover features of the products they did not know about, but appeared to be relevant for the product's context of use - "Funnily enough when I go to the reviews, I realise more attributes of the product. So, I haven't thought about it before but really is important when I go to the reviews I notice that" [P9].
Many sites do not provide enough information to support a thorough exploration of their products' capabilities and limitations. For this reason, participants turn to reviews; their number and variety providing a good base for exploration - "Like on Amazon when you buy something they just put up a photo and there is very little information, so when you read through you get an idea of what you're actually going to be getting" [P6]. Reviews also support brand comparison, participants reporting on instances when their choice of one brand or another was based entirely on the information obtained from reviews - "There are brands in South Africa that you wouldn't know about unless you lived in South Africa. And I looked at how people compared them to the better-known brands and it actually turned out that the South African one was a much better one based on the opinion of other people" [P17].

\subsubsection{Quality Verification}

Assessing the quality of a product or service is largely done through reviews. Participants rely on reviews when trying to assess the quality level of products they are less familiar with, or products whose quality is difficult to assess without specialised knowledge or expertise - "For some things I don't know very well or some things I don't know how to measure the quality very well, I would put a lot of trust in reviews" [P2].

\subsubsection{Validation}

Reviews are used to validate characteristics of a product or service about to be purchased. Participants were interested in confirming that the product or service is good value for money and, in this context, this can be a double edged sword. On one hand, participants wanted the reassurance that they won't be ripped off buying the products or the service. On the other hand, labelling a product as "value for money" raised credibility concerns "I become suspicious sometimes, I really do. This makes me very suspicious. When people in Argos for example, they say it is a good value for money, so in a way I look at it as look, it is not excellent, but for the money you pay, it is ok'. It might have a negative effect on me. Obviously if I am realistic I understand that, but it demotivates me" [P9]. Participants also consult reviews to make sure that the product description provided by the seller is accurate, and realistically matches what the product is actually like - "All of the main manufacturers are telling you that [the phone] it's got an amazing screen. Chances are it's not, so the reviews are good to tell you if it's really a good screen or they just tell it's a good screen" [P13].

Surprisingly, participants noted they also used reviews after buying a product or a service. If the product does not work as expected, they want to 
make sure that other buyers experienced the same problem - "Maybe, if something went wrong with the app and I wouldn't know what went wrong, I would read reviews to make sure that other people have had this experience and it is not just me. If it's just me, maybe l'm doing something wrong. But if someone else has had this experience, maybe you know... it's just the app" [P3]. If the experience with the product or the service turns out to be far worse than expected, participants wanted to reevaluate their own decision- making, and identify the characteristics first missed when consulting the reviews, if indeed they initially consulted them.

\subsubsection{Experience, Judgement, and Expertise Proxy}

The one thing all participants looked for in reviews is the reviewer's description of his/her experience with the product. Reviews were seen as a proxy for such direct experience, allowing participants to indirectly experience the product through others - "The idea of reviews, at least for me, is that you don't have direct access to the product while people that wrote the review, theoretically, have already had the experience of the product" [P20] or "Well, it's like actually using a product without buying it" [P1]. Additionally, participants felt that reviews provide proof of the product's impartial test by various buyers in different environments - "I often like to match benchmarks with realistic tests. Like sometimes when you look at mobile phones, they have some tricks applied so that they get better results from benchmarks, but then in reality you know that they are the same as the other adversaries in the market. So I usually want to look upon how the real life experiences compare to the benchmarks and then again, check that the real life experience is enough or not enough for my own experience" [P5]. Participants acknowledged that making a purchase decision consumes time and energy, but builds a framework of judgment around the product under consideration in the mind of the buyer. Such a structure provides details around the motives the review author had for considering the product purchase, the characteristics of the product $\mathrm{s} / \mathrm{he}$ was interested in and tried to assess, and the train of thought that led him/her to buy the product. When this framework is accompanied by validated direct experience with the product it becomes even more valuable and, therefore, prone to being reused - "Also, it is a sort of reusability of other people's judgment so instead of playing with your own mind which sometimes is energy consuming, you are reusing other peoples' judgment" [P9].

Together with direct experience and personal judgment of a product, reviews are also seen as a replacement of expertise in the case of specialised products, where an expert's opinion would normally be required for assessing the product.

\subsubsection{Social Proof}

Reviews play a social role; participants regard them as bonding tools among buyers or, what P9 calls, a "social proof" that people have a tendency to look for. P12 underlines the idea that "collectively we understand things better than individually", allowing people with different perspectives, interests, and expectations to draw the profile of a product for the benefit of its future buyers - "It is good to see a general impression of this item and how people see it in a different spectrum - cost, quality of material, insurance, delivery, payment method, customer serve, after sale. All of these..." [P12].

\subsubsection{Safety Net}

Participants noted that they used reviews to mitigate the risk of disappointment when shopping online - "But when you order online, you're excited, wait for the post, you open it up and it's not what you expected. It's the whole fuss of re-packing it, returning it, waiting for your money to be refunded, and then start all over to get another product. And l've gone through that and it's a very disappointing feeling, it's like a kid getting the wrong present for Christmas" [P7]. Reviews are also used as a warning tool about product features that are either poorly implemented, or deceptive. Such features are intrinsically difficult to assess for experience goods, but may also be difficult to assess for service goods without prior experience with the product; such features may not be adequately described by the seller - "I am interested to see what other people have to say, just to see if there's anything that I should be worried about. So, if I'm looking at, let's say, a second edition of a book and then someone says that it is exactly the same as the first edition and I have the first edition, I might choose not to actually buy the second edition" [P2].

\subsubsection{Confidence Builder}

Consulting reviews determines how warranted skepticism around cheaper products or products on sale might be. Products that are cheaper than what participants would expect may be poor quality; reviews are often consulted to check whether that is indeed the case. Similarly, if a product's price is lowered, participants consult reviews to make sure this is not due to problems the seller is trying to hide - "And now, because it was reduced, I wanted to make sure it's not because something is not quite right with it" [P7]. Lesser known sellers are subject to more investigation, and participants build confidence in them through other buyers' reviews "So if I was trying to find a product that I couldn't get through amazon and I would have to go through a private seller, then I would use the reviews even 
more just to see what the other customers have told, how's the process, have they sent it on time, I don't know..." [P6]. Reviews are also used to build confidence in decision-making; participants want assurance they have chosen the right product for their needs. Fearing that the repercussions of a poor decision would make them regret it, the participants want to convince themselves that the decision is the right one - "Sometimes I use reviews to reinforce my belief that I made the right choice. It can happen. Just to confirm to myself... Yeah, I think this is the best option..." [P17].

\subsection{Usable Online Reviews}

All participants agreed that contextualised reviews weigh much more than short one-line reviews. Participants identified three types of contextual information they look for in reviews: a) in depth details about the product, b) balanced arguments in favour and against purchasing the product, and c) personal stories. As P3 puts it, "If the review is detailed, it's got a strong feel to it, coming from someone who's clearly invested to made a difference with it, then I would trust it". This information provides additional assurance that the review author purchased and tested the product himself, thereby diminishing skepticism that the review was purchased or faked - "And then l've also heard that some companies could pay to get some positive reviews which makes it a little more worrying. You just tell them how many excellent you want, how many average, what kind of a scale you want and they just get reviews for you"[P14].

In addition to context, participants appreciate structure in reviews, their favourite structure templates being bullet points ("Bullet points would make a lot of difference"[P9]), pros versus cons ("I would say pros and cons is my favourite like you can see what's good and what's bad with it. I don't like it when people elite just cons or just pros. A good mixture is always nice, especially when you're buying products"[P18]), and topic based ("Well, basically, I am used to reviews that are structured in a way that the reviewer tells why he bought the product because then I get to know what his opinion about the product is before he bought it and then that he examines all the parts of the product itself like the casing, the actual quality of the product, how it's been made"[P5]).

Several types of 'anti-patterns' for reviews stood out in our discussions with participants. One-liner reviews, for example, tend to be skipped as: "they don't really sum up anything, they don't really tell you anything" [P18]. Completely positive reviews raise skepticism and distrust in the true motives of the reviewer. As P4 puts it: "But, of course, if you note that they are $100 \%$ positive, you'll start thinking ' $\mathrm{hmm} . .$. is this a real review? Is it just somebody from the company who wrote it?"' Completely negative reviews were also approached with a degree of skepticism. Issues like the reviewer author's personality, their knowledge of the product, or their mood at the time they wrote the review are influencing factors in the tone and the content of the review. As P11 puts it: "Well, usually there are extremely negative people and balanced people. Balanced people can provide both positive and negative aspects in one review. You can say the wifi was not working, but the people were nice. Whereas a negative person would be like the wifi was not working, everything was terrible. So, overall, you need to have a sense of the person."

The number of reviews garnered by a product is important. In the words of P3, “Well, I wouldn't trust a review, but if I read several reviews that say pretty much the same thing, then I would trust them, yes". A higher number of reviews for a specific product provide confidence that more people have actually tested the product, and there is a general consensus over its quality. This is particularly relevant when having to choose between similar products in terms of prices, rating, and functionality. P6 explained: "Sometimes I was hesitant about a review or to buy something if there was little reviews on it. Whereas if you go to boots.com or whatever and you want to buy a face cream and there is 80 reviews, it kind of gives you that confidence that 'ok, at least 80 people have bought this and the general consensus is that it is a pretty good product'; Whereas if there was a similar one but there was only 2 reviews, I would be very reluctant to buy something on just what 2 other people have said."

Review consumers can also be influenced by the language and tone of reviews. Bad grammar, an angry tone, and the use of expletives were used by several participants $(P 1,3,6,8,9,11,15)$ as review filters - "If it something that's from the top of someone's head or it's not even spelled correctly or something that is 3 words and a cursing word, then I wouldn't put too much value on that" [P3]. Moreover, badly written reviews and completely negative reviews are often synonymous; as P6 puts it: "So reviews which are completely negative, they are badly written, they have bad grammar, they use bad language, I would just completely discard them. I don't think they are giving a relevant opinion on what you're actually buying."

\subsection{The Use of Online Reviews}

We identified a set of drivers that, combined, flesh out review consumer strategies for making sense of the ever-growing number of online reviews (Table 2). These drivers are of three types: a) 


\begin{tabular}{|c|c|c|}
\hline Driver & Description & Quote \\
\hline Price & $\begin{array}{l}\text { Only read reviews for products within a specific price } \\
\text { range }\end{array}$ & $\begin{array}{l}\text { "I think I would start with understanding how much money I would pay for a product } \\
\text { and then look for reviews in that category" [P8] }\end{array}$ \\
\hline Rating & $\begin{array}{l}\text { Only read reviews for products with a specific overall } \\
\text { rating }\end{array}$ & $\begin{array}{l}\text { "At first, when I am just scrolling through the products, I am just looking at the rating } \\
\text { they give to the product. And if there is a good rating associated with the product, } \\
\text { then I look deeper in the review" [P5] }\end{array}$ \\
\hline Fault & Read reviews associated with a lower rating first & $\begin{array}{l}\text { "I first read the negative reviews and check if they really have substance or are just } \\
\text { thrown like that 'I don't like the product" [P10] }\end{array}$ \\
\hline Interest & Scan reviews for comments on characteristics of interest & $\begin{array}{l}\text { "I mean a product could have characteristics that are not important to me. } \\
\text { For example, for a phone, it can say that its camera is very good or not very good. } \\
\text { But I am not necessarily interested in the camera. I just want to know that the phone } \\
\text { is working without 'stumbling'. The camera is not important, so I only read the bits } \\
\text { of reviews that are of interest to me. If it says that the battery is poor, then yes, } \\
\text { I would be bothered by that." [P1] }\end{array}$ \\
\hline Consensus & $\begin{array}{l}\text { Keep reading reviews until there is a clear consensus } \\
\text { among them }\end{array}$ & $\begin{array}{l}\text { "If I read them and they are mixed, positive and negative, I read as many as I need } \\
\text { to convince myself that the product is good or bad" [P1] }\end{array}$ \\
\hline Sessions & Read reviews over multiple sessions & $\begin{array}{l}\text { "I do think a lot of time like I never see it today, I'm going to order it today. Ilook at it, } \\
\text { I read some reviews, I think about it, I think about it again, I read some other reviews. } \\
\text { Yeah, I don't really rush into ok, I want this, I'm ordering it now, I don't care" [P7] }\end{array}$ \\
\hline Volume & $\begin{array}{l}\text { Only read reviews for products which have more than } \\
\mathrm{X} \text { reviews }\end{array}$ & $\begin{array}{l}\text { "I would not bother reading the reviews of something that has } 2 \text { or } 3 \text { reviews } \\
\text { to begin with" [P3] }\end{array}$ \\
\hline Date & Only read reviews posted in the last $\mathrm{X}$ months & $\begin{array}{l}\text { "Yeah, Ilook at the most recent reviews. If there hasn't been any review posted in } \\
2 \text { years, I kind of tend to move to something else" [P7] }\end{array}$ \\
\hline Outliners & $\begin{array}{l}\text { Read a few reviews associated with higher ratings } \\
\text { and a few associated with lower ratings }\end{array}$ & $\begin{array}{l}\text { "It's the overall score which they've received and then the top category, the excellent } \\
\text { one, I tend to check to see what's good about it and then the poor category, I check } \\
\text { to see what is wrong with the product and that is the one that helps me to decide" } \\
{[P 14]}\end{array}$ \\
\hline Order & Read reviews in the order they are presented by default & "I just read the reviews in the order that they are presented to me" [P2] \\
\hline Search engine & $\begin{array}{l}\text { Read the results returned by a search engine for } \\
\text { "reviews for X" }\end{array}$ & $\begin{array}{l}\text { "I just google 'reviews for } X \text { product' and look at as many results I come across until } \\
\text { I get bored. If they are consistently good or consistently bad, then I either buy it or } \\
\text { not" [P7] }\end{array}$ \\
\hline Length & Only read reviews of a certain length; skip the one liners & $\begin{array}{l}\text { "I would look at these lengthy revs because you get the lengthy revs and then you } \\
\text { get the short comments almost like comments revs. So I would look at the lengthy } \\
\text { review, the longer description that I can find about the product I am trying to make } \\
\text { sense of, what is actually like" [P8] }\end{array}$ \\
\hline Keywords & $\begin{array}{l}\text { Search for keywords using the browser and read the } \\
\text { fragments around the keywords }\end{array}$ & $\begin{array}{l}\text { "If I am interested in breakfast, I would use the browser to search the page for } \\
\text { keywords" [P20] }\end{array}$ \\
\hline
\end{tabular}

Table 2: Approaches in consulting online reviews

a discrete variable characterising the product or the buyer (price of the product, product's overall rating, product's faults, number of reviews for the product, date of the review, and outliner reviews of the product), b) a stopping condition, or c) both (length of the reviews, buyer's interests, and keywords). Stopping conditions apply to the cases where review consumers keep reading a set of reviews (the set presented by the site or the results returned by a search engine) until a certain condition is met. Examples of such conditions are: getting an understanding over the consensus among a product's reviews, the review consumer feeling like s/he has enough information to make a decision, or simply the review consumer getting bored (in which case, multiple session for consulting the reviews of a product will occur). In the case where both a variable and a stopping condition determine the strategy of the consumer, the number of reviews filtered based on the variable is not known to the consumer and needs, therefore, consulting sequentially until a stop condition is met (e.g. reading all the reviews longer than a paragraph requires going through all the reviews sequentially until a stopping condition is met and manually choosing the longer ones to read).

These drivers are not considered in isolation, but combined to match the level of investment the review consumer has in the purchase decision. This level of investment matches the level of complexity (both in terms of time and strategy) that the consumers employ when consulting reviews, and may be determined by a set of factors. Economic value and duration of use are examples of such factors, with consumers being more invested in consulting reviews for expensive products, or products used over long periods of time. As P15 puts it,"it depends on the economic value of it and how much l'm going to use it, how does it do with my comfort as well. If I need a chair, I would look very carefully at it, if I'm buying a pen or anything even at the same cost but it is not close than... It has to do with the user and the economic value". Having used the product before is enough of an indication about its performance, so re-reading reviews of a previously used product is not something participants were concerned about. However, services do appear to change over time, so reviews are a constant tool participants employ when booking them - "if you buy the same face cream for 20 years, it doesn't change. But hotels, they change from 6 months to 6 months, so yeah, I would [read reviews of hotels l've stayed at before]" [P6]. Similarly, not knowing the seller and the policies they employ is a decisive factor when consulting reviews - "So if I was trying to find a product that I couldn't get through amazon and I would have to go through a private seller, then I would use the reviews even more just to see what the other customers have 
told, how's the process, have they sent it on time, I don't know..." [P6].

Purchasing a specialised product (e.g. fishing kit, professional camera) or a product that participants know little about biases the use of a more complex strategy when consulting reviews. However, reviews are not the only tool participants employ when making a purchase decision for this class of products. On one hand, they need more technical knowledge about the product that reviews usually offer - "I think if I didn't know much about the cameras, I would possibly read the technical manuals first just to know what exactly could go wrong, what exactly is the camera about. And then, I would read people's experiences with the camera to make sure that those technical aspects are covered and how, the quality they are covered at" [P3]. On the other hand, negative reviews for such products may derive from the lack of expertise and experience of the reviewer in using the product and are, therefore, of little use - "You could have someone who didn't read the instructions on how to use the camera and thinking that it doesn't work properly. But he only says that cause he doesn't know how the camera works" [P3].

\subsection{Who is the Review Author?}

Currently, few reviews sites provide information about the review authors; most of the time, this information is limited to age, gender, location, account name, and possibly some form of avatar. From our interviews, it became obvious that several details about the review authors are particularly relevant to review consumers. The detail participants found most important was assurance that the reviewer had actually used the product or the service the review was written for. Sites like booking.com and amazon.com appeared to provide this assurance to participants - "Also, has this person purchased it. On Amazon they do this, they verify that the person purchased it, that's very useful as well. So even if it is the supplier or the manufacturer, they still have to buy it themselves" [P19].

Although existing reviews sites focus mostly on the identity details of review authors, little of this detail appears to interest participants, whose interest is limited only to characteristics relevant to the product review. As P6 puts it, "I suppose it depends, like if I was buying clothes it would be good to know their size and their age. If I was buying toys, it would be good to know if they actually have kids, so are they grannies or mums who are actually reviewing? I would trust them because they would have more insights into these products then I do". Similarly, reviews for services are only screened based on the generic type of traveller rather than by any in-depth details pertaining to the reviewer - "But what I tend to do is when I'm booking hotels, I tend to look at the individual's details as well. If I am booking a holiday and then I am going with the kids, is it family friendly? If the hotel says yes, then I would check were there any families there so I would first tend to focus on moms and dads writing reviews" [P14].

Participants are primarily interested in three different types of information about review authors: a) their expertise with the product they review ("I wouldn't want to know who the person who wrote a review is, but I would want to know what he knows about the topic" [P3]), b) their expectations from the product or the service ("It can just be 'I wanted something else'... people can have different expectations from products and I am very well aware of that so I wouldn't take a review like that as on objective fact of a product. I would try to understand what they were expecting and why they like it or not like it" [P8]), and c) their reviewing history (i.e. what other reviews have they posted across various sites and for what products or services).

Participants felt that while identity details can be faked, the level of expertise of the review author, their expectations, and reviewing history are difficult to tamper with, and can often be guessed from cues embedded in the review's text. The reviewing history draws a portrait of the review author, which may be telling of the author's expertise (someone who has reviewed similar products before has more experience with that class of products) and expectations (someone who has badly reviewed a 4star hotel might be prone to badly review a 2-star hotel due to higher expectations).

The participants noted two particular characteristics of reviewing history of common interest: the number and frequency of the reviews posted. A review author with a single, one-line review may be considered suspicious. However, a detailed, elaborated review from an infrequent review author appears more credible and therefore, influential - "someone who's never written a review in their whole life... for them to take the time and write a review when they never do it, it might have been a really bad experience" [P18]. Posting reviews too frequently may typecast a review author as a "professional reviewer" by those who expect review authors to strike a balance in terms of the frequency and the content they post - "if it's someone that spends all his time reviewing, I might not like it too much. Like a professional reviewer or something... If it's someone that writes 10-20 reviews in a year, and some are good some are bad, then great" [P20]. 


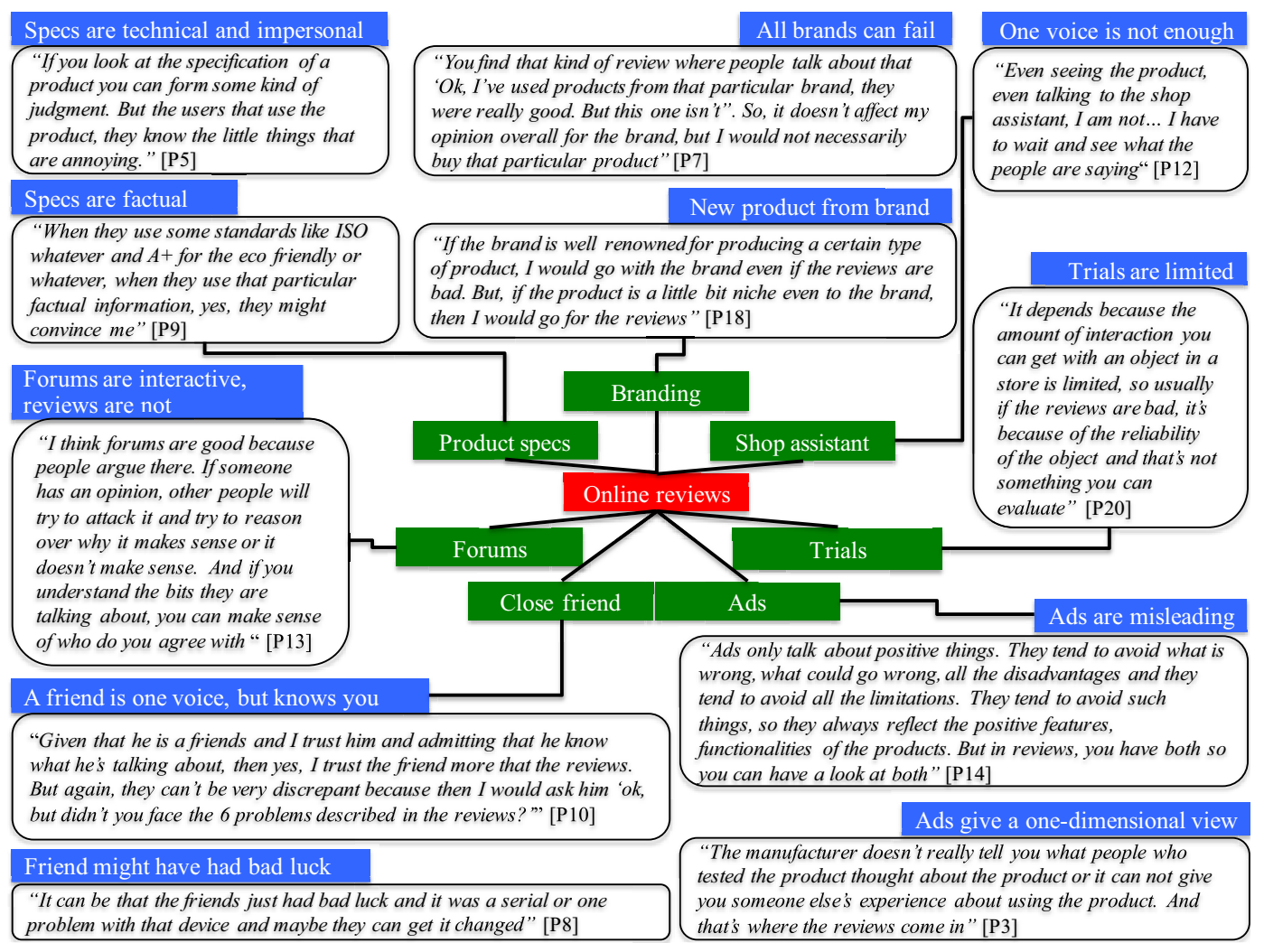

Figure 1: Reviews versus other e-commerce tools

\subsection{The Place of Online Reviews}

As previously mentioned in Section 4.3, reviews are not the only tool review consumers use when making purchase decisions online or offline. Branding, product specifications, advertisements (ads), shop assistants, forums, close friends, ratings, and direct experience are all means used by review consumers to collect information and support their decisions (Figure 1). While brands may inspire confidence in the decision, they do not appear to be more convincing than reviews. Participants felt that all brands could, at some point in their existence, produce a less successful product; they also believed that new or niche products from a brand might not rise to the same standards as previous products. Similarly, ads are seen as providing only one dimension of the product - the seller's, which is biased, thereby omitting any negative aspects or under-developed features of the product.

Participants welcomed recommendations for products or services from close friends or shop assistants, but agreed that the friend and the shopkeeper were only single voices as opposed to reviews, which provide feedback from a larger and more diverse population. Additionally, shopkeepers were perceived as prone to give positive recommendations from the seller's perspective, while negative recommendations from friends may be due to exceptional circumstances, where friends were simply unlucky.

Review consumers usually see testing a product on the shop floor before purchase as a helpful tool. In this context, participants were asked how would they go about making a purchase decision when their experience with the product differed from the general consensus gleaned from online reviews available for that product. Where reviews were positive, but the product trial was negative, the general consensus among participants was that direct experience overshadowed the reviews. As P10 puts it: "It all goes from the idea that I want to buy something. The reviews cannot convince me more than I convinced myself from the product specification or a like... It does not work the other way around". In the reverse case, however, (i.e. when reviews are negative, but the participants' product trial was positive), participants were ambivalent for three reasons. First, they felt that reviews provided added value because trialling the product in a store is time limited; this time may not be long enough to fully understand the product's idiosyncrasies - "If it's really negative and a lot of people said negative things, I would reconsider buying it because in the shop, if I had a positive experience with it, it can be 10 minutes or 15 minutes. But if people actually 
bought it and they've been using it for a longer time, and there is a bug that comes out after a week or so, I wouldn't know it based in my experience in the shop" [P8]. Second, seeing the product in the store does not always allow experiencing it in the environment and the context it was designed for; this makes it difficult to make an informed decision over the behaviour and quality of the product without consulting reviews - "I would be very hesitant, I would probably wait and then try it again. I don't know... I just think, especially when you buy items like in camping and you don't actually know much about them, it's very easy to say in a shop oh, they look pretty, but then when you are actually out in the field then something doesn't work" [P6]. Third, when participants directly experience the product, while reviews do not influence them in matters related to aesthetics or personal preferences, they do play an important role when investigating product qualities like longevity, reliability, maintainability - "It depends on the contradiction. If he's saying oh, I don't like the way it feels, I wouldn't buy it, you know... it's personal preference. If he's saying oh, I used it for 6 months and then it broke, I can't tell so it would probably put me off buying it" [P19].

\section{DISCUSSION AND DESIGN IMPLICATIONS}

In this paper, we described a study on the role, use, and place of online reviews. In doing so, we have made three contributions. First, we have characterised the emergent roles played by online reviews. Second, we have described the review consumer's expectations for 'usable' review, together with the cues used when ascertaining the trustworthiness of a review's author. Third, we have presented strategies employed by review consumers when making sense of a body of reviews, and the relationships between reviews and other artefacts used when evaluating products and services.

We now consider some of the design implications of our work for both review authors and review consumers.

\subsection{Review Authors}

Although the focus of this paper has been on review consumers, our work has shed some light on what is expected from review authors as well. For example, factual information about a product or service is seen as far more convincing than opinions lacking arguments (either of a positive or negative nature). Personal stories, arguments in favour or against buying a product or a service, and in-depth details about the product and its use are seen as the most valuable and convincing forms of information review consumers look for in reviews. This implies that templates for such classifications would provide useful cues for authors wishing to provide impartial insights to consumers.

As the findings from Section 4.2 also indicate, 'anti-patterns' such as poor spelling and an angry writing tone can detract review consumers from the content of a review. Consequently, additional tools for checking for spelling or typographical errors, or examining the sentiment of review content can help authors moderate reviews before they are made publicly available.

\subsection{Review Consumers}

The results in Section 4.5 suggest that, when evaluating a product or service, decision making is difficult when consumers are faced with negative reviews, but a positive user experience. On such occasions, graphical, visual, audio, or video material can help paint a credible and realistic picture of a product or service in context.

Review sites usually consider reviews only for the pre-purchase assessment of a product or service, but our results in Section 4.1 show that review consumers use reviews for a range of different reasons before, during, and after a purchase decision is made. Given these different roles, review consumers might consume multiple reviews, but are equally likely to consume a single review before referring to some other artefact such as a relevant forum post or advert. While these artefacts may distract a review consumer from reviews, they may also suggest new search criteria for reviews. Consequently, in addition to providing a means for review consumers to browse collections of reviews, we should also consider how best to support their journey through the "web of reviews" and review related content.

Given the value placed in reviews, we should also think about how consumers can be directed to the most relevant reviews given their context of use. The current state of the art in reviewbased recommendation systems combines review elements, such as keywords and review author opinions, in order to recommend products based on consulted reviews (Chen et al. 2015). Our results complement this work by suggesting review elements that might be consulted when review consumers employ different review strategies. If properly exploited, different combinations of review elements might also be used to recommend reviews, rather than products, of interest.

Proposing design patterns for human-review interaction is beyond the scope of this paper, but we believe 
the drivers presented in Section 4.3 may be useful when evaluating their implementation.

\section{REFERENCES}

BBC News (2015). Online reviews used as blackmail. http: //www.bbc.co.uk/news/ business-33184207.

Chatterjee, P. (2001). Online Reviews: Do Consumers Use Them? In ACR 2001 Proceedings, pages 129-134. Association for Consumer Research.

Chen, L., Chen, G., and Wang, F. (2015). Recommender systems based on user reviews: the state of the art. User Modeling and UserAdapted Interaction, 25(2):99-154.

Dohse, K. (2013). Fabricating Feedback: Blurring the Lines Between Brand Management and Bogus Reviews. Journal of Law, Technology \& Policy, 2013:363-392.

Forman, C., Ghose, A., and Wiesenfeld, B. (2006). Examining the Relationship Between Reviews and Sales: The Role of Reviewer Identity Disclosure in Electronic Markets. Information Systems Research.

Gretzel, U., Yoo, K. H., and Purifoy, M. (2007). Online travel review study: Role and impact of online travel reviews. Technical report, Texas $A$ \& M University. Department of Recreation, Park and Tourism Sciences. Laboratory for Intelligent Systems in Tourism.

Hedegaard, S. and Simonsen, J. G. (2013). Extracting usability and user experience information from online user reviews. In Proceedings of the SIGCHI Conference on Human Factors in Computing Systems, CHI '13, pages 2089-2098. ACM.

Hu, N., Liu, L., and Zhang, J. J. (2008). Do online reviews affect product sales? the role of reviewer characteristics and temporal effects. Inf. Technol. and Management, 9(3):201-214.

Huang, A. H., Chen, K., Yen, D. C., and Tran, T. P. (2015). A study of factors that contribute to online review helpfulness. Computers in Human Behavior, 48:17-27.

lacob, C., Harrison, R., and Faily, S. (2013). Online Reviews as First Class Artifacts in Mobile App Development. In Proceedings of the 5th International Conference on Mobile Computing, Applications, and Services (MobiCASE), pages 47-53. Springer.
Jin, H., Sakai, T., and Yatani, K. (2014). Reviewcollage: A mobile interface for direct comparison using online reviews. In Proceedings of the 16th International Conference on Human-computer Interaction with Mobile Devices \&\#38; Services, MobileHCl '14, pages 349-358. ACM.

Kang, J. S., Kuznetsova, P., Luca, M., and Choi, Y. (2013). Where not to eat? improving public policy by predicting hygiene inspections using online reviews. In Proceedings of the 2013 Conference on Empirical Methods in Natural Language Processing, pages 1443-1448.

Lee, J., Park, D.-H., and Han, I. (2008). The effect of negative online consumer reviews on product attitude: An information processing view. Electron. Commer. Rec. Appl., 7(3):341-352.

Leskovec, J. (2016). Web data: Amazon Reviews. https://snap.stanford.edu/data/ web-Amazon .html.

Luca, M. (2011). Reviews, Reputation, and Revenue: The Case of Yelp.Com. Technical report, Harvard Business School NOM Unit Working Paper No. 12016.

Mudambi, S. M. and Schuff, D. (2010). What makes a helpful online review? a study of customer reviews on amazon.com. MIS Q., 34(1):185-200.

TripAdvisor LLC (2016). Fact Sheet. https : //www . tripadvisor.co.uk/PressCenter-c4-Fact_ Sheet.html.

Vermeulen, I. E. and Seegers, D. (2009). Tried and tested: The impact of online hotel reviews on consumer consideration. Tourism Management, $30(1): 123-127$.

Ye, Q., Law, R., and Gu, B. (2009). The impact of online user reviews on hotel room sales. International Journal of Hospitality Management, 28(1):180 - 182.

Yoo, C. W., Sanders, G. L., and Moon, J. (2013). Exploring the effect of e-WOM participation on e-Loyalty in e-commerce. Decision Support Systems, 55(3):669- 678.

Yoo, K.-H. and Gretzel, U. (2011). Influence of personality on travel-related consumer-generated media creation. Comput. Hum. Behav., 27(2):609621. 